\title{
Marital Interactions as Predictors of Symptoms Severity in Panic Disorder with Agoraphobia
}

\author{
Ghassan El-Baalbaki (Corresponding author) \\ Department of Psychology, Université du Québec À Montreal (UQAM) \\ C.P. 8888, succursale Centre-Ville, Montréal, Québec, H3C 3P8, Canada \\ Tel: 1-514-987-3000 \# 2038 E-mail: el-baalbaki.ghassan@uqam.ca \\ Claude Bélanger \\ Université du Québec À Montreal (UQAM) \\ $\&$ \\ McGill University and Douglas Hospital Research Center, Canada \\ Tel: 1-514-987-3000 \# 1777 E-mail: belanger.claude@uqam.ca
}

\author{
Steffany J. Fredman \\ Massachusetts General Hospital
}

$\&$

Harvard Medical School

One Bowdoin Square, 6th Floor, Boston, MA 02114, Canada

Tel: 1-617-643-6703 E-mail: sfredman@partners.org

Donald H. Baucom

Department of Psychology, University of North Carolina at Chapel Hill

UNC-CH, Chapel Hill, NC 27599-3270, USA

Tel: 1-919-9625035 E-mail: don_baucom@unc.edu

Roger Marcaurelle

Université du Québec À Montreal (UQAM), Canada

Tel: 1-514-987-3000 \# $4800 \quad$ E-mail: marcaurelle.roger@uqam.ca

André Marchand

Université du Québec À Montreal (UQAM)

$\&$

Fernand-Seguin Research Center, L.H. Lafontaine Hospital, Canada

Tel: 1-514-987-3000 \# 8439 E-mail: marchand.andre@uqam.ca

Received: August 31, $2011 \quad$ Accepted: September 29, $2011 \quad$ Published: December 1, 2011

doi:10.5539/ijps.v3n2p107 URL: http://dx.doi.org/10.5539/ijps.v3n2p107

\begin{abstract}
Several studies showed associations among marital variables and panic disorder with agoraphobia (PDA) symptomatology. However, very few explored this issue using behavioural coding of couples' interactions. We
\end{abstract}


conducted this study to investigate whether observed marital interaction patterns would predict PDA severity.

Cross-sectional, pre-treatment multi-center study of 65 married couples in which one spouse was diagnosed with panic disorder with agoraphobia (PDA).

All participants completed seven self-reported PDA symptoms measures commonly used in PDA research and two self-reported marital measures. Couples were observed during a 15-minute video-taped problem-solving task. The spouses' marital interactions were coded by two independent coders using two validated observational coding systems.

After controlling for socio-economical variables, the presence of negative marital interaction patterns, namely criticism and dominance behaviour, predicted higher symptom severity, whereas the presence of positive interaction patterns, namely support and validation behaviours, predicted lower symptom severity . Emotional over-involvement of the non-PDA partner, a manifestation of expressed emotions, failed to predict PDA severity.

Discord in the couple could exacerbate the PDA and maintain it. A therapist evaluating a married PDA client may need to assess his or her client's marital interaction patterns with his or her partner and adjust his intervention accordingly.

Keywords: Panic disorder, Agoraphobia, Marital relationship, Observational coding, Expressed emotion (EE), Emotional over-involvement (EOI)

\section{Introduction}

The association between panic disorder with agoraphobia (PDA) and relationship adjustment has been examined in several studies. Barlow, Wade, Monroe, and Michelson (1993) and Kleiner and Marshall (1987) noted that among other stressors, marital conflicts, divorce, and interpersonal stress are often present in the year preceding the onset of the disorder. Scott, Wells, Angermeyer, Brugha, Bromet, \& et al. (2010), found that marital status was linked to risk of mood, anxiety and substance use onset and varied between men and women. More specifically they showed that being in first marriage was associated with reduced risk for depressive disorders and panic disorder in men, while being previously married (separated, divorced, widowed, remarried) was associated with increased risk of onset in both men and women and the association in the case of depressive disorders was stronger for men. Untreated PDA was reported to negatively affect the level of marital and social functioning (Markowitz, Weissman, Ouellette, Lish, \& Klerman, 1989; Weissman, 1991). Moreover, Craske and Zoellner (1995a) note that a dysfunctional relationship may contribute to the maintenance of the disorder. However, findings are inconsistent regarding the extent to which marriages of couples with a PDA spouse differ from those of other couples. For example, some studies show that PDA couples report lower marital adjustment and marital satisfaction than non-PDA couples (Fauerbach, 1992; Kleiner, 1987; Lange \& Van Dyck, 1992; McCarthy \& Shean, 1996), whereas other studies found comparable levels between PDA and non-PDA couples (Emmelkamp \& Gerlsma, 1994; Fisher \& Wilson, 1985; Powers, 1984). Nonetheless, Chambless et al. (2002), consistent with findings reported by Arrindell and Emmelkamp (1986), found that, although PDA couples reported significantly lower marital adjustment than did non-PDA couples, the level of marital dissatisfaction was not high when compared with norms for maritally distressed couples.

\subsection{PDA and Interpersonal and Problem-solving Skills}

When compared to control groups, patients meeting a diagnosis of PDA are rated as more submissive and non-assertive (Eher et al., 2002), more inhibited and dependent (Hafner \& Minge, 1989; Shean \& Uchenwa, 1990), and less self-confident (McCarthy \& Shean, 1996). They also tend to show a less problem-focused coping style (Roy-Byrne, Vitaliano, Cowley, Luciano, \& et al., 1992). Of note, the severity of PDA symptoms has been found to correlate positively with submission and non-assertiveness (Eher et al., 2002). PDA patients report comparable or higher levels of interpersonal problems than depressed and other psychiatric patients do (Arrindell \& Emmelkamp, 1986; Oppenheimer \& Frey, 1993). One theory to explain the association between PDA and interpersonal problems is that the limitations caused by their phobias drive agoraphobic individuals to seek high levels of social support, which in turn increases demands on relatives, friends, and spouses. Such demands may exhaust the resources of their significant others (Chambless et al., 2002), thereby generating interpersonal stress.

Problem-solving skills appear to be a moderating factor of the impact of stressful events on anxiety (Nezu, 1986), suggesting that when individuals with lower problem-solving skills are confronted with stressful events their anxiety tends to be higher. Brodbeck and Michelson (1987) showed that agoraphobic women generate significantly fewer effective solutions during a problem-solving task than do control subjects, and Chambless et al. (2002) found that they propose significantly fewer solutions than their husbands do. Moreover, an association has been found between depression and difficulties with social and problem-solving skills. Verbal interactions of 
depressed spouses and their partners tend to be characterized by dysphoric affect and the expression of psychological and somatic complaints. Exchanges on both sides tend to be more negative, less cooperative, and more asymmetrical (Hautzinger, Linden, \& Hoffman, 1982; McCabe \& Gotlib, 1993; Merikangas, Ranelli, \& Kupfer, 1979; Perez, Pettit, David, Kistner, \& Joiner, 2001; Segrin, 2001). Given that depression is the most frequent comorbid disorder of PDA, occurring in at least $24 \%$ of the patients (Brown \& Barlow, 2002; Gorman \& Coplan, 1996), we expected that PDA patients would show deficits in social and problem-solving skills.

Depression is strongly related to marital dissatisfaction (Whisman, 2001); marital adjustment is correlated with the quality of couples' problem-solving skills (Bélanger, Dulude, Sabourin, \& Wright, 1993), and couples' ability to solve problems is correlated with PDA treatment outcome (Marcaurelle, Bélanger, \& Marchand, 2003). Therefore, an exploration of the associations among marital adjustment, marital interaction during problem-solving situations, and the severity of PDA is the focus of the present investigation.

Chambless et al. (2002), using behavioral observation to evaluate communication during a problem-solving task, found evidence to support of the hypothesis that agoraphobic severity and the quality of marital interactions are related. In that study, husbands of agoraphobic women were found to be more critical of their wives. Criticism and negative verbal behavior of husbands toward their agoraphobic wives were positively correlated with the severity of avoidance behavior. Agoraphobic wives who were more avoidant engaged in less positive verbal behaviors, more negative verbal behaviors, and less self-disclosure. However, the study only examined couples with agoraphobic wives; thus, it is unclear whether these findings generalize to couples with male agoraphobic partners.

\subsection{Emotional Over-involvement and PDA}

Relatives of psychiatric patients are considered to be high in expressed emotion (EE; Leff \& Vaughn, 1985) when they show high levels of criticism, hostility, criticism, or emotional over-involvement (EOI) in reference to the patient. Chambless and Steketee (1999) note that EE, particularly hostile criticism by relatives, is a strong predictor of poor treatment outcome for anxiety disorders. However, they also note that non-hostile criticism (e.g., dissatisfaction with patients' anxiety-related behaviors without rejecting the patient as a person) is associated with less avoidance. Several studies report associations between relatives' emotional over-involvement (EOI) and poor treatment outcome for psychiatric patients, including those with anxiety disorders (Chambless \& Steketee, 1999). More work is needed, however, to determine the role of the specific elements of EOI - that is, intrusiveness, excessively self-sacrificing behavior, or exaggerated emotional response to the patient's illness - in predicting PDA symptom severity. For instance, it is possible that when non-anxious partners engage in high levels of excessively self-sacrificing behavior (e.g., taking over chores and responsibilities for PDA partners to diminish their anxiety), they reinforce the PDA spouses' dependence and avoidance behaviors. Similarly, the presence of an exaggerated emotional response manifested by melodramatic statements and attitudes towards the PDA spouse's limitations and fears may, for example, reinforce the PDA spouse's own catastrophic thoughts and fear of bodily sensations.

Finally, it is worth noting that Chambless, Caputo, Jasin, Gracely, and Williams (1985) and de Jong and Bouman (1995) showed that the level of education, the couple's income and the occupational status predict fear of consequences of anxiety, fear of bodily sensations, and agoraphobic avoidance. Thus, to properly account for the association of the marital interaction variables with PDA severity, the impact of socio-economic variables were investigated.

\subsection{Research Hypotheses}

Given the associations among marital adjustment, interpersonal and problem-solving skills, EOI by partners, and PDA symptomatology, we conducted this study to investigate the following hypotheses: (a) Negative marital problem-solving interaction patterns will predict higher symptom severity of PDA, whereas positive problem-solving interaction patterns will predict lower symptom severity of PDA; and (b) the presence of EOI in the non-anxious (NPDA) spouse will predict higher PDA symptom severity.

Results deriving from preliminary statistical analyses are presented. Therefore we will also discuss the following observations: (a) differences between PDA men and PDA women in terms of symptom severity; (b) differences between PDA and NPDA spouses in terms of marital adjustment; (c) differences in marital adjustment and marital interaction patterns due to gender of PDA and NPDA spouses; (d) links between marital adjustment and PDA symptom severity; (e) links between marital adjustment and quality of interaction patterns within the couple; (f) links between depression and marital adjustment and interaction patterns; and (g) links between socio-economic variables and PDA symptom severity. 


\section{Method}

\subsection{Participants}

The sample consists of 65 heterosexual couples in which one spouse meets the criteria of the Diagnostic and Statistical Manual of Mental Disorders (DSM-IV; American Psychiatric Association, 1994) for a primary diagnosis of panic disorder with agoraphobia (PDA), according to the Anxiety Disorders Interview Schedule, Lifetime Version (ADIS-IV-L; DiNardo, Brown, \& Barlow, 1994). The higher ratio in women (2:1) reported by White and Barlow (2002), is reflected in our sample of 19 men and 46 women with PDA. The mean age of PDA patients is 39.17 ( $S D=8.98$, range: 22 - 64), and the average illness duration is 12 years $(S D=9.7$, range: 0.5 40). PDA patients have on average 11.92 years of schooling $(S D=3.98$, range: 0 - 24). Most hold a part-time or a full-time job (61\%), and $74 \%$ take a psychotropic medication. On average, all participants have been cohabiting, with or without marriage, for 11.4 years $(S D=9.42$, range: $1-40)$ and have one child $(M=1.08, S D$ $=1.21$, range: $0-4)$. On average, the time spent living together while one partner had PDA is 6.85 years $(S D=$ 6.84 , range: $1-34)$.

Recruitment of this sample occurred through advertisements in the Montreal metropolitan area local newspapers $(N=47)$, at the Douglas Hospital Anxiety Clinic $(N=12)$, and at the Centre for Intervention for Cognitive Behavioral Therapy at Louis-H. Lafontaine Hospital $(N=6)$.

To be included in this study, participants had to meet the following criteria: (a) age between 18 and 65; (b) married or cohabitating with the same partner for at least one year; (c) a primary DSM-IV diagnosis of PDA assigned by a psychiatrist; (d) a primary diagnosis of PDA according to the ADIS-IV-L (DiNardo, Brown, \& Barlow, 1994), with a clinical severity rating of four on a scale ranging from zero (none) to eight (very severely disturbing-disabling) and present for at least six months; and (e) if a secondary DSM-IV axis I diagnosis was present, its clinical severity rating according to the ADIS-IV-L should be two or more levels lower than the PDA rating. Exclusion criteria included: (a) the presence of substance-related, psychotic, or bipolar disorders; (b) the presence of any unstable medical condition; and (c) the presence of mental retardation.

\subsection{Measures}

In addition to the assessment of the overall clinical severity of PDA using the ADIS-IV-L interview during the selection process, all participants completed a battery of questionnaires, including a general information socio-demographic questionnaire - constructed by the authors for the needs of this study — and seven self-reported PDA symptoms measures that were used in their French-Canadian validated versions and their Cronbach's index of internal consistency $(\alpha)$ varies between 0.74 and 0.94 . The following self-reported measures were used: the body sensations questionnaire (BSQ) and the agoraphobic cognitions questionnaire (ACQ) (Chambless, Caputo, Bright, \& Gallagher, 1984), the mobility inventory for agoraphobia (MIA) (Chambless, Caputo, Jasin, Gracely, \& Williams, 1985), the anxiety sensitivity index (ASI) (Reiss, Peterson, Gursky, \& McNally, 1986), the Beck Anxiety Inventory (BAI) (Beck, Epstein, Brown, \& Steer, 1988), and the Beck Depression Inventory-II (BDI-II) (Beck, Steer, \& Brown, 1996).

To measure marital functioning we used two self-reported marital measures, a brief version of Spanier's dyadic adjustment scale, the DAS-4 (Sabourin, Valois, \& Lussier, 2005) and the questionnaire for the sources of agreement and disagreement (QSAD) (Bourgeois, Sabourin, \& Wright, 1990) and two observational coding systems of the spouses' marital interactions, the global couple interaction coding system (GCICS) (Bélanger, Dulude, Sabourin, \& Wright, 1993) and the observational coding system for emotional over-involvement (EOI) (Fredman, Chambless, \& Steketee, 2004).

The DAS-4 Dyadic Adjustment Scale -4 (Sabourin, Valois, \& Lussier, 2005) composed of 4 questions is a brief French-Canadian validated version based on the original 32-items Dyadic Adjustment Scale proposed by Spanier (1976). The authors of this short version proved that it could be used as a continuous measure of couple adjustment and to categorize participants into distressed and non-distressed groups. In our study, Cronbach's index of internal consistency was 0.85 for the PDA spouses and 0.80 for the non-PDA partners.

The GCICS is a macro-level coding system used to code video-taped marital problem-solving interactions. It evaluates each partner on five components of their verbal and non-verbal marital interaction during a problem-solving situation. Behaviors are rated according to four levels of severity (absent- mild- moderateexcessive). The five components of the GCICS are divided into three negative dimensions: (a) avoidance of, and withdrawal from, the discussion, (b) dominance, asymmetry in the control of the conversation, and (c) hostility, criticism and conflict; and two positive dimensions: (a) support and validation, which reflect active listening and warmth; and (b) problem-solving skills. The latter dimension is composed of two sub-categories: (1) efforts at 
clarification and negotiation, desire to find solutions, and (2) quality of proposed solutions.

The observational coding system for EOI, permits individual ratings for intrusiveness, excessive self-sacrifice and exaggerated emotional response displayed by the relative (parent, spouse, and sibling) of a psychiatric patient during a video-taped problem-solving interaction. Each dimension is scored on a scale that ranges from none (1) to marked (5). Following Leff and Vaughn (1985), the authors of this coding system define (a) intrusiveness as the relative's attempt to exert psychological or physiological control over the patient's well-being through age-inappropriate means, overprotection, and control, (b) excessive self-sacrifice as the relative's consistently and unreasonably placing the patient's needs ahead of his or her needs, and (c) exaggerated emotional response to the patient's illness as the relative's excessive anxiety directly related to the patient's welfare as shown by excessive emotionality, empathy, or melodrama regarding the patient's well being.

The videotapes were coded by two different graduate students in clinical psychology, trained to criterion by the first author of this study, one coded with the GCICS and the other with the EOI coding system. The coders were unaware of the research hypotheses. The first author served as the reliability coder for both the training and research samples. We tested interrater reliability using tapes of 25 couples randomly selected, and it was proved to be excellent for all dimensions of GCICS $\rho_{\mathrm{I}}(3,1)=[0.63 ; 0.94]$ and for all dimensions of the EOI coding system $\rho_{\mathrm{I}}(3,1)=[0.95 ; .99]$ (Shrout \& Fleiss, 1979).

\subsection{Procedure}

\subsubsection{Selection of Participants}

Following a telephone preliminary screening, all participants were assessed with the ADIS-IV-L by an experienced advanced graduate student in clinical psychology. Participants with a primary diagnosis of PDA were then evaluated by a psychiatrist to confirm the diagnosis and absence of exclusion criteria. Interrater reliability test of PDA diagnosis and PDA severity according to the ADIS-IV-L, showed a strong concordance with a Kappa coefficient of 0.77. All PDA patients and their spouses provided informed consent.

\subsubsection{Interaction Task}

The participants were invited with their partners to one of the participating clinics for the videotaped problem-solving interaction task. We proposed a topic for the discussion that both partners found to be a source of moderate conflict and agreed to discuss. The couple was then left with the instructions to discuss the problem for 15 minutes and to work toward finding solutions that would mutually satisfy them. This procedure is very reliable even when one spouse has a clinical disorder, and it is commonly used in marital research to identify interaction patterns in couples (Weiss \& Heyman, 1997).

\section{Results}

\subsection{General and Descriptive Results}

\subsubsection{Group Homogeneity}

One-way ANOVA results demonstrated that participants recruited from advertisements did not differ from those recruited from either one of the two participating clinics in terms of PDA baseline symptoms, marital adjustment, and problem-solving interaction ( $p s>.05)$.

In terms of depression symptoms as measured by the BDI-II, 73\% of PDA patients (13 men and 45 women) reported a comorbid depression (BDI cutoff score $\geq 11$ ). Results from a one-way ANOVA showed that patients from both clinics scored significantly higher than those recruited from advertisement, $F(1,63)=4.81, \eta^{2}=.07$, $p<.05$. In addition, patients coming from the two clinics had lower levels of education, $F(1,63)=5.18, \eta^{2}=.08$, $p<.05$, and a lower individual income $F(1,59)=5.9, \eta^{2}=.09, p<.05$, reflecting a lower socio-economical status than those recruited from advertisement. Monroe and Hadjiyannakis (2002) showed that a lower socio-economical status is a significant factor in depression, which may account for why patients from the two clinics showed higher depression symptoms. Sample homogeneity was confirmed in terms of PDA baseline symptoms, marital adjustment, and problem-solving interaction according to medication intake with another one-way ANOVA $(N=60)$ that showed no significant differences $(p s>.05)$ between the two groups.

\subsubsection{PDA Symptom Severity and Marital Adjustment in the Sample}

We report in Table 1 the means and standard deviation of the PDA symptoms severity in our sample as well as those of the clinical population as reported in the validation studies.

In terms of marital adjustment according to the DAS, our sample showed that the majority of spouses were maritally adjusted (42 PDA spouses and 43 NPDA spouses). Repeated measures ANOVA showed an interaction 
between the gender of PDA respondents and the marital adjustment of their partners $F(1,63)=6.0, \eta^{2}=.09, p$ $<.02$. Further inspection revealed that PDA men had a higher level of marital adjustment than their wives, whereas PDA women were less maritally adjusted than their husbands. Tests to examine within-subjects effects showed that DAS scores of PDA patients, independently from gender effect, are not significantly different than those of their partners. The Pearson correlation of marital adjustment between partners was strong $(r=.72, p$ $<.0001)$.

\subsubsection{Marital Interaction in the Sample According to the GCICS and the EOI Coding Systems}

Due to the non-normal distribution of severity for each measured dimension in the sample, we reduced the severity ranges of GCICS and EOI to two (absent and present), thus creating dichotomized variables. For each dimension of the GCICS, we performed a McNemar test for paired data to verify whether the coded behavior significantly differ according to the presence or not of PDA and found no difference ( $p s>.22)$, meaning that the presence or absence of a behavior is independent of the presence or absence of PDA. Positive inter-correlations for each dimension are found between spouses ( $r s=.30$ to $.60, p s<.05)$, as shown in Table 2, indicating that the presence of a behavior in one partner is linked to the presence of the same behavior in the spouse, which explains the previous result.

In order to compare the coded behaviors on the GCICS according to gender and to the presence or not of the illness, we performed a hierarchical log-linear analysis. Results show that an interaction effect is present between the gender of the subjects, the presence of PDA, and the presence of criticism and hostility behaviors during a problem-solving interaction, $\chi^{2}(1, N=65)=6,82, \phi=.32, p<.01$. The results suggest that PDA women are more critical than PDA men, and NPDA men are more critical than NPDA women, whereas NPDA men are more critical than PDA men, and PDA women are more critical than NPDA women.

For the EOI variables, Pearson chi-square tests showed no difference between the EOI behaviors of NPDA men and NPDA women $(p s>.10)$

\subsection{Preliminary Correlation Analyses of Variables for Prediction Tests}

\subsubsection{Analyses of Marital Interaction Variables with Marital Adjustment}

When PDA patients reported lower marital adjustment on the dyadic adjustment scale, they were more likely to criticize their partner during the problem-solving interaction $(r=-.33, p<.007)$. Similar findings were observed for NPDA partners regarding critical behavior $(r=-.34, p<.006)$. They also showed a tendency to dominate the interaction $(r=-27, p<.03)$. A higher level of marital adjustment in the PDA patient was associated with NPDA partners' displaying more support and validation $(r=.35, p<.005)$. Marital adjustment of the NPDA participant was only linked to his tendency of showing support and validation. No correlations were found in our sample, between the EOI of NPDA spouses and the dyadic adjustment of the PDA and NPDA partners.

\subsubsection{Analyses of Socioeconomic Variables and Marital Variables}

Pearson correlation analyses showed that better marital adjustment in PDA patients was associated with a higher household income $(r=.37, p<.003)$ and more children $(r=.30, p<.02)$. The NPDA spouse marital adjustment was higher in partners with higher education $(r=.30, p<.016)$. When asked if PDA causes marital conflicts, $20 \%$ of the PDA spouses reported that it never did, $43 \%$ reported that it sometimes causes conflict, $32 \%$ said it often did, and 5\% answered by saying that PDA always causes marital conflicts. Pearson correlations showed that when PDA patients report a higher frequency of marital problems caused by the disorder they tend, like their NPDA partners, to be less maritally adjusted (respectively $r=-.40, p<.001$ and $r=-.46, p<.0001$ ). The only marital interaction variable that showed a link with a socio-economical variable is that of the NPDA spouse's tendency to give support and validation when the illness appears after cohabitating $\chi^{2}(1, N=65)=5.28, \phi=.28$, $p<.02$. None of the EOI variables were significantly linked to any of the socio-economical variables.

\subsubsection{Analysis of Socio-economical Variables and PDA Severity}

A one-way ANOVA showed that when unaccompanied, men tend to engage in less avoidance of feared situations than women do $F(1,63)=4.45, \eta^{2}=.07, p<.04$. Pearson correlation analyses reveal several other associations reported in Table 3.

Finally, according to two independent one-way ANOVAs: (a) patients score lower on the Beck Anxiety Index, if they had the illness before cohabitating $F(1,62)=16.07, \eta^{2}=.21, p<.0001$, and (b) they avoid more phobic situations when they are accompanied than those who start experiencing PDA after cohabitating $F(1,63)=4.98$, $\eta^{2}=.07, p<.03$. 


\subsubsection{Correlation Analysis of Marital Variables and PDA Severity}

Marital Interaction and PDA Severity. Pearson correlations presented in Table 4 show that the presence of negative interaction patterns shown by the PDA and the NPDA spouses during a problem solving task tend to reflect a higher severity of PDA symptomatology, such that the severity of PDA symptomatology tends to be lower when couples manifest positive interaction patterns.

Marital Adjustment and PDA severity. Pearson correlations presented in Table 5 show that marital distress reported by PDA patients and NPDA spouses is linked to higher severity in PDA symptomatology.

\subsection{Tests of Predictions}

\subsubsection{Marital Interaction Predictors of PDA Severity}

In test the hypothesis that the quality of marital interaction patterns predicts PDA symptom severity, we performed a hierarchical regression analysis. In step 1, we included all socio-economical variables. To control collinearity within these variables, we retained only those with the higher magnitude of correlation with PDA variables. In step 2, we included all marital interaction variables for both the PDA and NPDA spouses by magnitude of correlation, to determine whether or not they add a predictive value to the variables in step 1, and, if so, which dimensions are the best predictors of PDA severity as measured by the seven self-reported PDA symptoms measures.

Results, presented in Table 6, show that PDA patients and NPDA partners' marital interaction behaviors provide additional predictive power to socio-economical variables. From the PDA patients' side, presence of dominating and controlling behavior during problem-solving predicts a higher PDA clinical severity (as per ADIS-IV-L). PDA spouses' critical behavior toward their NPDA partners predicts a stronger severity of anxiety symptoms. It also appears that presence of a better quality of solutions offered by the PDA patients predicts lower fear of bodily sensations. Dominance on the part of the NPDA partner predicts the presence of more catastrophic thoughts, while criticism and hostile behavior predicts a higher fear of bodily sensations and a stronger fear of consequences of anxiety symptoms. Finally, the presence of support and validation from the NPDA partners during problem-solving predicts lower agoraphobic avoidance when accompanied. None of the PDA patients or their NPDA partners' marital interaction variables predicts agoraphobic avoidance when unaccompanied, or severity of depression symptoms.

\section{Discussion}

This study seeks to elucidate several aspects of the associations between marital relationships and PDA. Although approximately two thirds of our sample, including PDA and non-PDA spouses, showed to be maritally adjusted, the PDA sample presents with high symptoms severity. Though one could argue that this observation seem counter to the basis of this study's rationale, it is nevertheless not surprising. The level of adjustment in the couple was measured with the DAS-4, and it could be that results from this self-report questionnaire are distorted by the very dysfunctional aspects of the marital relationship that this instrument is meant to identify, particularly by denial or avoidance of problems or conflicts. In fact, studies noted that couples in which one spouse is suffering from PDA have a tendency to deny marital problems (Mead, 1982) or to avoid them (Tillotson, 1992). Moreover, Zaider, Heimberg \& Iida (2010), in a study where they examined the impact of wives anxiety on the quality of their intimate relationship, by measuring daily mood, found that the relationship quality fluctuated in association with wives' daily anxiety and this was not impacted by DAS scores. Hence, our interest in using observational coding systems, during a problem solving situation, was to measure marital behaviours and study their predictive value of PDA symptom severity.

Our first hypothesis, that negative problem-solving patterns would predict higher PDA symptom severity and that positive interaction patterns would predict lower PDA symptom severity, was confirmed. The correlation analysis supports the hypothesis for all marital interaction variables except withdrawal. After controlling for socio-economic variables in the hierarchical regression, we found that dominance and criticism from PDA spouses predict respectively higher PDA clinical severity and higher severity of anxiety symptoms. Given that a low perception of control over a problematic situation is believed to be linked to the aetiology and maintenance of panic disorder (Barlow, 2002), it is likely that PDA partners with higher symptom severity present dominant and critical interpersonal behavior with their NPDA spouses. Driven by their need to preserve their perceived control over the situation as a protective strategy to buffer anxiety symptoms they may be feeling during the marital interaction. As for NPDA spouses, the presence of dominance and criticism in their problem-solving interaction patterns predicts higher catastrophic thoughts, higher fear of bodily sensations, and higher fear of consequences of anxiety in their PDA partner. It is possible that NPDA partners are, on the one hand, 
overwhelmed in their daily life by the limitations of their spouses with more severe fears - as evidenced by their criticism behavior - and, on the other hand, compelled to take charge of problematic situations - as demonstrated by their dominant behavior. Positive marital interaction variables, namely the presence of good quality solutions shown by the PDA spouse, predict lower fear of his bodily sensations, and the presence of support and validation shown by the NPDA spouse predicts lower severity of avoidance in the PDA partner when accompanied. Marcaurelle et al. (2005) found that PDA clinical severity and fear of bodily sensations increased as problem-solving confidence and involvement in problem-solving activities decreased in PDA patients. It is possible that PDA patients who generate constructive solutions to problems may have enhanced confidence in their problem-solving abilities and more involvement in the problem-solving activity, consistent with our findings. It is very likely that supportive and validating behaviors by NPDA spouses during a marital problem-solving task generalize to situations in which PDA partners' fears are elicited in anxiety-provoking situations and have the effect of increasing a sense of security in the PDA partner which, in turn, decreases agoraphobic avoidance.

We also wanted to test the hypothesis that emotional over-involvement (EOI) in the NPDA partner would predict higher PDA symptom severity and vice versa. Results did not support this hypothesis, as EOI failed to predict PDA symptom severity. This lack of association between PDA symptom severity and EOI might be due to the fact that the couples were assigned a problem related to a general marital source of conflict during the problem-solving task, and not a problem related to the anxiety disorder, rendering the manifestation of behavior like intrusiveness or exaggerated emotional response less likely to appear and contributing to a restricted range in the EOI variables. For that matter, Chambless et al. (2002) suggest that talking about the wife's agoraphobia instead of another topic may show more significant differences in problem-solving behavior within the couple.

Concerning our question about whether men and women differ in terms of PDA symptom severity, our results showed that PDA men avoid less than PDA women do, mainly when they have to face the phobic situations alone. This could be explained by differences in sex roles as mentioned by Fodor (1974), who stipulates that fearful behavior is culturally more acceptable for women than it is for men, and as argued by Hafner and Minge (1989), who showed that agoraphobic women perceive themselves as less autonomous. The deficit of masculine traits in agoraphobic women as described by Haimo and Blitman (1985) is consistent with this interpretation. Our results with respect to avoidance behavior being more present in PDA women than in PDA men are similar to those of other studies (Chambless \& Mason, 1986; Hafner, 1981; Turgeon, Marchand, \& Dupuis, 1998).

Regarding the comparison of the marital adjustment of PDA subjects with the marital adjustment of NPDA spouses in the sample, we found no difference between them. These results are not a comparison between clinical and non-clinical control group couples, and, therefore, should be viewed as the reflection of the strong correlation of marital adjustment between partners in our sample. When we investigated whether gender differences affect the marital adjustment of PDA and NPDA spouses, we found that PDA and NPDA wives were less adjusted than their male spouses. An explanation, based on differences in sex roles, is that female partners may be culturally predisposed to find their husbands' phobic behavior unacceptable (Marcaurelle, Belanger, Marchand, Katerelos, \& Mainguy, 2005), whereas agoraphobic women expect more support from their husbands and tend to describe them as not particularly helpful in making things better (McCarthy \& Shean, 1996; Pyke \& Roberts, 1987). As a result, agoraphobic women will perceive this lack of support as more distressing to the relationship.

Regarding the relation between gender and marital interaction patterns, our findings show that PDA women are significantly more critical than PDA men. Given that agoraphobic women tend to seek social support when facing a stressor (Vitaliano, Katon, Russo, Maiuro, \& et al., 1987; Vollrath \& Angst, 1993) and that agoraphobic women tend to find their husbands unhelpful (McCarthy \& Shean, 1996; Pyke \& Roberts, 1987), it is possible that their need for social support from their husband is unsatisfied, thereby leading them to be critical of their male partners. In contrast, because PDA men tend to be more preoccupied with somatic fears (Hafner, 1981) and less avoidant, they may need less support from their NPDA wives, and therefore tend to be less critical than PDA women. In addition, our results show that NPDA men are more critical than NPDA women. One explanation is that NPDA men, overwhelmed by the limitations of their spouses and the limits of their own resources in helping their agoraphobic wives, will tend to exert more pressure by showing more hostile and critical behaviors during the problem-solving task to facilitate their wives independence when the solution involves facing situations with phobic features; in contrast, NPDA women may be less critical then NPDA men because they may not have the same feeling of exhaustion of their own resources, given that PDA men tend, as noted above, to be less avoidant during feared situations. Another possible explanation is that NPDA women are more likely to attribute the limitations of their PDA husbands to the illness, while NPDA men may tend to view those limitations as under 
their PDA wives' control. Relatives of patients who tend to make responsibility attributions (relatives attribute the control of symptoms and problematic behaviors to personal variables within the patient, such as his personality or lack of willpower) were found to be higher in criticism and/or hostility when compared to those who tend to make illness attributions (i.e., they attribute problematic behaviors to the patient's illness) (Barrowclough \& Hooley, 2003; Renshaw, Chambless, \& Steketee, 2006).

Finally, we found that PDA symptomatology tends to be more severe when the dyadic adjustment of PDA or NPDA spouses was lower. In addition, it appears that the presence of negative interaction patterns in both the PDA and the NPDA spouse are linked to a lower dyadic adjustment in the couple whereas the presence of positive interaction patterns are linked to a better one. Living in a negative environment could serve as a general stressor to an anxious individual and/or living with a severely symptomatic partner could create more tension and stress.

\subsection{Implication and Limitations of Our Study and Future Directions}

Our findings support the idea that a therapist evaluating a married PDA client may need to assess his or her client's marital interaction patterns with his partner. Discord in the couple has a negative impact on communication and problem-solving, leading to hostility and negative affect. This, in turn, could exacerbate the PDA and maintain it, making standard cognitive-behavioral therapy less effective. It is also possible that the PDA contributes to the marital distress and discord in the first place. Hence, it may also be beneficial to add to the standard cognitive-behavioral treatment of PDA, a marital intervention focusing on improving communication training and problem-solving between partners and altering structural patterns in the relationship that maintain symptom expression or interfere with exposure-based activities for the PDA spouse.

There are also several limitations associated with this study. First, we did not have a non-clinical control group to compare the marital variables of our subjects to the normal population. Second, due to procedural limitations, we did not evaluate the NPDA partners' psychiatric condition. Nevertheless, though accounting for the presence of psychopathology in the NPDA spouse could bring more light to the understanding of whether their observed behaviors are influenced or not by a psychiatric disorder, this study's main objective was to clarify the relation between marital dynamics and PDA severity. Third, the problem-solving task was not related to the disorder and, as such, may not have pulled for disorder-relevant behavior patterns that contribute to the maintenance of the agoraphobia and marital distress. This has also made these behaviors difficult to measure observationally and may have contributed to the non-normal distribution of marital interaction variables and emotional over-involvement that obliged us to dichotomize the range of severity of behaviors to present and absent, thus limiting the extent of the interpretation of correlation analysis. Finally, even though the sample does represent the population in terms of sex composition, statistically, an unequal cell sizes by a 2:1 proportion is a limitation.

Future research needs to evaluate couples-based treatment programs and study their effect both on PDA symptomatology and marital adjustment. It would be also of interest to broaden the scope of our comprehension of PDA marital dynamics to ethnic groups and same-sex couples to determine whether the observed patterns observed in this sample generalize to other types of couples.

\section{References}

American Psychiatric Association. (1994). Diagnostic and Statistical Manual of Mental Disorders (4th ed.). Washington, DC, US: American Psychiatric Publishing, Inc.

Arrindell, W. A., \& Emmelkamp, P. M. (1986). Marital adjustment, intimacy and needs in female agoraphobics and their partners: A controlled study. British Journal of Psychiatry Vol 149 Nov 1986, 592-602 http://dx.doi.org/10.1192\%2Fbjp.149.5.592

Barlow, D. H. (2002). Anxiety and its disorders: The nature and treatment of anxiety and panic (2nd ed.). New York, NY, US: Guilford Press, 704.

Barrowclough, C., \& Hooley, J. M. (2003). Attributions and expressed emotion: A review. Clinical Psychology Review, 23(6), 849-880. http://dx.doi.org/10.1016\%2FS0272-7358\%2803\%2900075-8

Beck, A. T., Epstein, N., Brown, G., \& Steer, R. A. (1988). An inventory for measuring clinical anxiety: Psychometric properties. Journal of Consulting and Clinical Psychology, 56(6), 893-897. http://dx.doi.org/10.1037\%2F0022-006X.56.6.893

Beck, A. T., Steer, R. A., \& Brown, G. K. (1996). Manual for Beck Depression Inventory-II. San Antonio, TX: Psychological Corporation.

Bélanger, C., Dulude, D., Sabourin, S. p., \& Wright, J. (1993). Preliminary validation of a global system for 
coding marital interactions/Validation préliminaire d'un système global de cotation des interactions conjugales. Canadian Journal of Behavioural Science, 25(4), 483-498. http://dx.doi.org/10.1037\%2Fh0078879

Bourgeois, L., Sabourin, S. p., \& Wright, J. (1990). Predictive validity of therapeutic alliance in group marital therapy. Journal of Consulting and Clinical Psychology, 58(5), 608-613. http://dx.doi.org/10.1037\%2F\%2F0022-006X.58.5.608

Brodbeck, C., \& Michelson, L. (1987). Problem-solving skills and attributional styles of agoraphobics. Cognitive Therapy and Research. Special Issue: Anxiety: Cognitive factors and the anxiety disorders, 11(5), 593-610. http://dx.doi.org/10.1007\%2FBF01183861

Brown, T. A., \& Barlow, D. H. (2002). Classification of anxiety and mood disorders. In D. H. Barlow (Ed.), Anxiety and its disorders. The nature and treatment of anxiety and panic (2nd ed., pp. 292-327). New York: The Guilford Press.

Chambless, D. L., Caputo, G. C., Bright, P., \& Gallagher, R. (1984). Assessment of fear of fear in agoraphobics: The Body Sensations Questionnaire and the Agoraphobic Cognitions Questionnaire. Journal of Consulting and Clinical Psychology, 52(6), 1090-1097. http://dx.doi.org/10.1037\%2F\%2F0022-006X.52.6.1090

Chambless, D. L., Caputo, G. C., Jasin, S. E., Gracely, E. J., \& Williams, C. (1985). The Mobility Inventory for Agoraphobia. Behaviour Research and Therapy, 23(1), 35-44. http://dx.doi.org/10.1016\%2F0005-7967\%2885\%2990140-8

Chambless, D. L., Fauerbach, J. A., Floyd, F. J., Wilson, K. A., Remen, A. L., \& Renneberg, B. (2002). Marital interaction of agoraphobic women: A controlled, behavioral observation study. Journal of Abnormal Psychology, 111(3), 502-512. http://dx.doi.org/10.1037\%2F\%2F0021-843X.111.3.502

Chambless, D. L., \& Mason, J. (1986). Sex, sex-role stereotyping and agoraphobia. Behaviour Research and Therapy, 24(2), 231-235. http://dx.doi.org/10.1016\%2F0005-7967\%2886\%2990098-7

Chambless, D. L., \& Steketee, G. (1999). Expressed emotion and behavior therapy outcome: A prospective study with obsessive-compulsive and agoraphobic outpatients. Journal of Consulting and Clinical Psychology, 67(5), 658-665. http://dx.doi.org/10.1037\%2F\%2F0022-006X.67.5.658

Craske, M. G., \& Zoellner, L. A. (1995). Anxiety disorders: The role of marital therapy. Jacobson, Neil S (Ed); Gurman, Alan S (Ed), (1995). Clinical handbook of couple therapy. (pp. 394-410). xi, NY, US: Guilford Press.

De Jong, G. M., \& Bouman, T. K. (1995). Panic disorder: A baseline period. Predictability of agoraphobic $\begin{array}{lllll}\text { avoidance behavior. Journal of Anxiety Disorders, } & 9(3), & \text { 185-199. }\end{array}$ http://dx.doi.org/10.1016\%2F0887-6185\%2895\%2900001-5

DiNardo, P. A., Brown, T. A., \& Barlow, D. H. (1994). Anxiety Disorders Interview Schedule for DSM-IV: Lifetime Version (ADIS-IV-L). N.Y: Graywind Publications.

Eher, R., Rau, H., Fruhwald, S., Ritter, K., Grunhut, C., Schmitt, M., et al. (2002). Intimate relationships of patients meeting a diagnosis of panic disorder/agoraphobia: Evidence for submissive and nonassertive conflict styles. Zeitschrift fur Klinische Psychologie und Psychotherapie: Forschung und Praxis Vol 31(1) 2002, 14-21. http://dx.doi.org/10.1026//1616-3443.31.1.14

Emmelkamp, P. M. G., \& Gerlsma, C. (1994). Marital functioning and the anxiety disorders. Behavior Therapy, 25(3), 407-429. http://dx.doi.org/10.1016\%2FS0005-7894\%2805\%2980155-8

Fauerbach, J. A. (1992). Marital interaction patterns of couples with and without an agoraphobic partner. Dissertation Abstracts International, 52(10-B), 5530-5531

Fisher, L. M., \& Wilson, G. T. (1985). A study of the psychology of agoraphobia. Behaviour Research and Therapy, 23(2), 97-107. http://dx.doi.org/10.1016\%2F0005-7967\%2885\%2990018-X

Fodor, I. G. (1974). The phobic syndrome in women: Implications for treatment. In Violet Franks \& Vasanti Burtle (eds.), Women in therapy. New York: Brunner/Mazel, 132-168

Fredman, S. J., Chambless, D. L., \& Steketee, G. (2004). Development and Validation of an Observational Coding System for Emotional Overinvolvement. Journal of Family Psychology, 18(2), 339-347. http://dx.doi.org/10.1037\%2F0893-3200.18.2.339

Gorman, J. M., \& Coplan, J. D. (1996). Comorbidity of depression and panic disorder. Journal of Clinical Psychiatry, 57(Suppl 10), 34-41

Hafner, R., \& Minge, P. J. (1989). Sex role stereotyping in women with agoraphobia and their husbands. Sex 
Roles, 20(11-12), 705-711. http://dx.doi.org/10.1007\%2FBF00288081

Hafner, R. J. (1981). Agoraphobia in men. Australian and New Zealand Journal of Psychiatry, 15(3), 243-249. http://dx.doi.org/10.3109\%2F00048678109159442

Haimo, S., \& Blitman, F. (1985). The effects of assertive training on sex role concept in female agoraphobics. Women \& Therapy, 4(2), 53-61. http://dx.doi.org/10.1300\%2FJ015V04N02_08

Hautzinger, M., Linden, M., \& Hoffman, N. (1982). Distressed couples with and without a depressed partner: an analysis of their verbal interaction. Journal of Behavior Therapy \& Experimental Psychiatry, 13(4), 307-314. http://dx.doi.org/10.1016\%2F0005-7916\%2882\%2990075-1

Kleiner, L. (1987). The relationship of interpersonal problems to the development and treatment of agoraphobia. Dissertation Abstracts International, 47(11-B), pp.

Kleiner, L., \& Marshall, W. (1987). The role of interpersonal problems in the development of agoraphobia with panic attacks. Journal of Anxiety Disorders, $1(4), \quad 313-323$. http://dx.doi.org/10.1016\%2F0887-6185\%2887\%2990011-9

Lange, A., \& Van Dyck, R. (1992). The function of agoraphobia in the marital relationship. Acta Psychiatrica Scandinavica, 85(1), 89-93. http://dx.doi.org/10.1111\%2Fj.1600-0447.1992.tb01449.x

Leff, J., \& Vaughn, C. (1985). Expressed emotion in families: Its significance for mental illness. New York: Guilford Press.

Marcaurelle, R., Bélanger, C., \& Marchand, A. (2003). Marital relationship and the treatment of panic disorder with agoraphobia: A critical review. Clinical Psychology Review, 23(2), 247-276. http://dx.doi.org/10.1016\%2FS0272-7358\%2802\%2900207-6

Marcaurelle, R., Belanger, C., Marchand, A., Katerelos, T. E., \& Mainguy, N. (2005). Marital predictors of symptom severity in panic disorder with agoraphobia. Journal of Anxiety Disorders, 19(2), 211-232. http://dx.doi.org/10.1016\%2Fj.janxdis.2004.01.005

Markowitz, J. S., Weissman, M. M., Ouellette, R., Lish, J. D., \& Klerman, G. (1989). Quality of life in panic disorder. Archives of General Psychiatry, 46(11), 984-992

McCabe, S. B., \& Gotlib, I. H. (1993). Interactions of couples with and without a depressed spouse: Self-report and observations of problem-solving situations. Journal of Social \& Personal Relationships, 10(4), 589-599. http://dx.doi.org/10.1177\%2F0265407593104007

McCarthy, L., \& Shean, G. (1996). Agoraphobia and interpersonal relationships. Journal of Anxiety Disorders, 10(6), 477-487. http://dx.doi.org/10.1016\%2FS0887-6185\%2896\%2900024-2

Mead, P. T. (1982). Interpersonal assessment of agoraphobia. Dissertation Abstracts International, 43(1-B), 295

Merikangas, K. R., Ranelli, C. J., \& Kupfer, D. J. (1979). Marital interaction in hospitalized depressed patients. $\begin{array}{lllll}\text { Journal of Nervous \& } \quad \text { Mental } & \text { Disease, } & \text { 167(11), }\end{array}$ http://dx.doi.org/10.1097\%2F00005053-197911000-00006

Monroe, S. M., \& Hadjiyannakis, K. (2002). The social environment and depression: Focusing on severe life stress. In I. H.Gotlib \& C.I. Hammen (Eds.). Handbook of Depression (pp. 314-340). New York: Guilford Press.

Nezu, A. M. (1986). Negative life stress and anxiety: Problem solving as a moderator variable. Psychological Reports, Vol 58(1) Feb 1986, 279-283. http://dx.doi.org/10.2466\%2Fpr0.1986.58.1.279

Oppenheimer, K., \& Frey, J. (1993). Family transitions and developmental processes in panic-disordered patients. Family Process, 32(3), 341-352. http://dx.doi.org/10.1111\%2Fj.1545-5300.1993.00341.x

Perez, M., Pettit, J. W., David, C. F., Kistner, J. A., \& Joiner, T. E., Jr. (2001). The interpersonal consequences of inflated self-esteem in an inpatient psychiatric youth sample. Journal of Consulting \& Clinical Psychology, 69(4), 712-716. http://dx.doi.org/10.1037\%2F\%2F0022-006X.69.4.712

Powers, J. F. (1984). Dimensions of agoraphobia in married women: Assertiveness, marital satisfaction and sex role influences. Dissertation Abstracts International, 45(2-B), 684-685

Pyke, J., \& Roberts, J. (1987). Social support and married agoraphobic women. Canadian Journal of Psychiatry, 32(2), 100-104

Reiss, S., Peterson, R. A., Gursky, D. M., \& McNally, R. J. (1986). Anxiety sensitivity, anxiety frequency and the predictions of fearfulness. Behaviour Research and Therapy, 24(1), 1-8. 
http://dx.doi.org/10.1016\%2F0005-7967\%2886\%2990143-9

Renshaw, K. D., Chambless, D. L., \& Steketee, G. (2006). The Relationship of Relatives' Attributions to Their Expressed Emotion and to Patients' Improvement in Treatment for Anxiety Disorders. Behavior Therapy, 37(2), 159-169. http://dx.doi.org/10.1016\%2Fj.beth.2005.11.001

Roy-Byrne, P. P., Vitaliano, P. P., Cowley, D. S., \& Luciano, G., et al. (1992). Coping in panic and major depressive disorder: Relative effects of symptom severity and diagnostic comorbidity. Journal of Nervous and Mental Disease, 180(3), 179-183

Sabourin, S., Valois, P., \& Lussier, Y. (2005). Development and Validation of a Brief Version of the Dyadic Adjustment Scale With a Nonparametric Item Analysis Model. Psychological Assessment, 17(1), 15-27. http://dx.doi.org/10.1037\%2F1040-3590.17.1.15

Scott, K.M., Wellsa, J.E., Angermeyera, M., Brughaa, T.S., Brometa, E., Demyttenaerea, K., de Girolamoa, G., Gurejea, O., Haroa, J.M., Jina, R., Karam, A.N., Kovessa, V., Lara, C., Levinsona, D., Ormela, J., Posada-Villaa, J., Sampsona, N., Takeshimaa, T., Zhanga, M., and Kesslera, R.C., (2010). Gender and the relationship between marital status and first onset of mood, anxiety and substance use disorders. Psychological Medicine, 40. http://dx.doi.org/10.1017\%2FS0033291709991942

Segrin, C. (2001). Interpersonal processes in psychological problems. New York, NY: Guilford Press.

Shean, G., \& Uchenwa, U. (1990). Interpersonal style and anxiety. Journal of Psychology: Interdisciplinary and Applied, 124(4), 403-408

Shrout, P. E., \& Fleiss, J. L. (1979). Intraclass correlations: Uses in assessing rater reliability. Psychological Bulletin, 86(2), 420-428. http://dx.doi.org/10.1037\%2F\%2F0033-2909.86.2.420

Spanier, G. B. (1976). Measuring dyadic adjustment: New scales for assessing the quality of marriage and similar dyads. Journal of Marriage \& the Family, 38(1), 15-28. http://dx.doi.org/10.2307\%2F350547

Tillotson, D. J. (1992). Connection, disconnection and intimacy in married agoraphobic women. Dissertation Abstracts International, 52(10-A), 3534-3534

Turgeon, L., Marchand, A., \& Dupuis, G. (1998). Clinical features in panic disorder with agoraphobia: A comparison of men and women. Journal of Anxiety Disorders, 12(6), 539-553. http://dx.doi.org/10.1016/S0887-6185(98)00031-0

Vitaliano, P. P., Katon, W., Russo, J., \& Maiuro, R. D., et al. (1987). Coping as an index of illness behavior in panic disorder. Journal of Nervous and Mental Disease, 175(2), 78-84. http://dx.doi.org/10.1097\%2F00005053-198702000-00002

Vollrath, M., \& Angst, J. (1993). Coping and illness behavior among young adults with panic. Journal of Nervous and Mental Disease, 181(5), 303-308. http://dx.doi.org/10.1097\%2F00005053-199305000-00005

Wade, S. L., Monroe, S. M., \& Michelson, L. K. (1993). Chronic life stress and treatment outcome in agoraphobia with panic attacks. American Journal of Psychiatry, 150(10), 1491-1495

Weiss, R. L., \& Heyman, R. E. (1997). A clinical-research overview of couples interactions. In W. K. Halford \& H. J. Markman (Eds.), Clinical handbook of marriage and couples intervention (pp. 13-41). Chichester, England: Wiley.

Weissman, M. M. (1991). Panic disorder: Impact on quality of life. Journal of Clinical Psychiatry, 52(2, Suppl), 6-8

Whisman, M. A. (2001). The association between depression and marital dissatisfaction. [References]. In S. R. H. Beach (Ed.), Marital and family processes in depression: A scientific foundation for clinical practice (pp. 3-24). Washington, DC: American Psychological Association. http://dx.doi.org/10.1037/10350-001

White, K. S., \& Barlow, D. H. (2002). Panic disorder and agoraphobia. In D. H. Barlow (Ed.), Anxiety and its disorders: the nature and treatment of anxiety and panic (2nd ed., pp. 328-379). London: The Guilford Press.

Zaider, T. I., Heimberg, R.G., \& Iida, M. (2010). Anxiety disorders and intimate relationships: A study of daily processes in couples. Journal of Abnormal psychology, 119 (1). http://dx.doi.org/10.1037\%2Fa0018473 
Table 1. Descriptive analysis of PDA symptom severity in the sample compared to PDA clinical population

\begin{tabular}{|l|l|l|l|l|}
\hline \multicolumn{2}{|c|}{ PDA variables (pre-test) } & \multicolumn{2}{c|}{ Study Sample } & \multicolumn{2}{c|}{$\begin{array}{c}\text { PDA clinical } \\
\text { population }\end{array}$} \\
\hline \multicolumn{1}{|c|}{ N=65 } & $M$ & $S D$ & $M$ & $S D$ \\
\hline ADIS-IV-L PDA severity & 5.81 & 1.06 & NA & NA \\
\hline Fear of bodily sensations (BSQ) & 3.10 & .75 & 3.05 & .86 \\
\hline Catastrophic thoughts (ACQ) & 2.65 & .62 & 2.43 & .63 \\
\hline Agoraphobic avoidance (accompanied) (MIAa) & 2.31 & .84 & 2.39 & .88 \\
\hline Agoraphobic avoidance (unaccompanied) (MIAu) & 3.25 & .81 & 3.22 & 1.01 \\
\hline Severity of anxiety symptoms (BAI) & 28.29 & 14.90 & 15.18 & 8.46 \\
\hline Fear of consequences of anxiety (ASI) & 33.69 & 11.05 & $(*)$ & $(*)$ \\
\hline Severity of Depression symptoms (BDI-II) & 18.71 & 10.16 & NA & NA \\
\hline
\end{tabular}

(*) Mean reported by Reiss et al. (1986) is 38.2 and only available for women with agoraphobia (n=9), standard deviation not available. Weighted Mean and Standard deviation in the normal population ( $n=147)$ are $M=18.2$; $\mathrm{SD}=9.3$

Table 2. Inter-correlations of GCICS dimensions between PDA spouse and NPDA partner

\begin{tabular}{|c|l|l|l|l|l|l|l|l|}
\hline \multicolumn{2}{|c|}{ GCICS dimension } & 1 & 2 & 3 & 4 & 5 & $5 \mathrm{a}$ & $5 \mathrm{~b}$ \\
\hline \multirow{5}{*}{ NPDA } & 1. Withdrawal & $.30^{*}$ & .20 & $.36^{* *}$ & -.05 & -.09 & -.16 & -.09 \\
\cline { 2 - 10 } & 2. Dominance & -.02 & $.53^{* *}$ & $.36^{* *}$ & -.05 & $.32^{*}$ & .07 & $.32^{*}$ \\
\cline { 2 - 10 } Partner & 3. Criticism and Hostility & -.17 & $.27^{*}$ & $.53^{* *}$ & -.13 & .21 & -.06 & .21 \\
\cline { 2 - 9 }$(N=65)$ & 4. Support and Validation & .07 & -.08 & -.23 & $.60^{* *}$ & $.25^{*}$ & .20 & $.25^{*}$ \\
\cline { 2 - 9 } & 5. Problem Solving Skills & .04 & .23 & .08 & .14 & $.47^{* *}$ & .12 & $.47^{* *}$ \\
\cline { 2 - 9 } & 5a. Clarification & .04 & .23 & .08 & .14 & $.47^{* *}$ & .12 & $.47^{* *}$ \\
\cline { 2 - 9 } & 5b. Quality of Solution & .02 & -.14 & -.05 & .17 & .14 & $.49^{* *}$ & .14 \\
\hline
\end{tabular}

* Correlation is significant at the 0.05 level (2-tailed).

** Correlation is significant at the 0.01 level (2-tailed). 
Table 3. Correlations of PDA severity and socio-economical variables

\begin{tabular}{|l|l|l|l|l|l|l|l|l|}
\hline $\begin{array}{l}\text { Socio-economical } \\
\text { Variables }\end{array}$ & $\begin{array}{l}\text { ADIS-IV-L } \\
\text { PDA } \\
\text { severity }\end{array}$ & $\begin{array}{l}\text { Fear of } \\
\text { bodily } \\
\text { sensations } \\
\text { (BSQ) }\end{array}$ & $\begin{array}{l}\text { Catastrophic } \\
\text { thoughts } \\
\text { (ACQ) }\end{array}$ & $\begin{array}{l}\text { Agoraphobic } \\
\text { avoidance } \\
\text { (accompanied) } \\
\text { (MIAa) }\end{array}$ & $\begin{array}{l}\text { Agoraphobic } \\
\text { avoidance } \\
\text { (unaccompanied) } \\
\text { (MIAu) }\end{array}$ & $\begin{array}{l}\text { Severity } \\
\text { of anxiety } \\
\text { symptoms } \\
\text { (BAI) }\end{array}$ & $\begin{array}{l}\text { Fear of } \\
\text { consequences } \\
\text { of anxiety } \\
\text { (ASI) }\end{array}$ & $\begin{array}{l}\text { Severity of } \\
\text { Depression } \\
\text { symptoms } \\
\text { (BDI-II) }\end{array}$ \\
\hline $\begin{array}{l}\text { Age of PDA } \\
\text { patient }\end{array}$ & -.06 & .22 & $.35^{* *}$ & .17 & .04 & .02 & .21 & .18 \\
\hline $\begin{array}{l}\text { Duration of } \\
\text { cohabiting }\end{array}$ & -.05 & .19 & $.29 *$ & -.08 & .04 & $.21^{*}$ & .17 & .14 \\
\hline Duration of PDA & .04 & .05 & .03 & .18 & $-.26^{*}$ & -.05 & -.03 \\
\hline $\begin{array}{l}\text { Number of } \\
\text { Children }\end{array}$ & -.09 & -.01 & -.14 & -.14 & -.03 & $.31^{*}$ & -.11 & $-.30^{*}$ \\
\hline $\begin{array}{l}\text { Household } \\
\text { income }\end{array}$ & -.04 & $-.43^{* *}$ & -.19 & $-.31 *$ & $-.34^{* *}$ & -.10 & $-.30^{*}$ & $-.26^{*}$ \\
\hline $\begin{array}{l}\text { Marital problems } \\
\text { caused by PDA }\end{array}$ & $.27 *$ & .17 & $.35^{* *}$ & .21 & .15 & -.05 & $.25 *$ & .05 \\
\hline
\end{tabular}

* Correlation is significant at the 0.05 level (2-tailed).

** Correlation is significant at the 0.01 level (2-tailed).

Table 4. Correlations of marital interaction variables (GCICS and EOI) and PDA severity

\begin{tabular}{|c|c|c|c|c|c|c|c|c|}
\hline $\begin{array}{l}\text { Marital Interaction } \\
\text { Variables }\end{array}$ & $\begin{array}{c}\text { PDA clinical } \\
\text { severity } \\
\text { (ADIS-IV-L } \\
\text { ) } \\
\end{array}$ & $\begin{array}{c}\text { Fear of } \\
\text { bodily } \\
\text { sensation } \\
\text { s (BSQ) }\end{array}$ & $\begin{array}{l}\text { Catastrophic } \\
\text { thoughts } \\
\text { (ACQ) }\end{array}$ & $\begin{array}{l}\text { Agoraphobic } \\
\text { avoidance } \\
\text { (accompanied } \\
\text { ) (MIAa) }\end{array}$ & $\begin{array}{l}\text { Agoraphobic } \\
\text { avoidance } \\
\text { (unaccompan } \\
\text { ied) (MIAu) } \\
\end{array}$ & $\begin{array}{c}\text { Severity } \\
\text { of anxiety } \\
\text { symptoms } \\
\text { (BAI) }\end{array}$ & $\begin{array}{c}\text { Fear of } \\
\text { consequences } \\
\text { of anxiety } \\
\text { (ASI) }\end{array}$ & $\begin{array}{c}\text { Severity of } \\
\text { Depression } \\
\text { symptoms } \\
\text { (BDI-II) } \\
\end{array}$ \\
\hline \multirow{2}{*}{\multicolumn{9}{|c|}{$\begin{array}{l}\text { PDA spouse }(N= \\
65) \\
\text { GCICS }\end{array}$}} \\
\hline & & & & & & & & \\
\hline Withdrawal & -.17 & -.30 & -.04 & .04 & -.12 & .09 & -.10 & -.06 \\
\hline Dominance & $.27^{*}$ & $.31 *$ & .24 & -.09 & .18 & $.28 *$ & $.31 *$ & .06 \\
\hline $\begin{array}{l}\text { Criticism and } \\
\text { Hostility }\end{array}$ & .19 & $.33 * *$ & $.32 * *$ & .13 & $.30 *$ & $.25^{*}$ & $.33 * *$ & .17 \\
\hline $\begin{array}{l}\text { Support-valid } \\
\text { ation }\end{array}$ & -.21 & -.001 & -.04 & -.13 & .01 & .02 & -.08 & .18 \\
\hline $\begin{array}{l}\text { Problem } \\
\text { solving skills }\end{array}$ & -.11 & .20 & .08 & -.03 & -.04 & .21 & .09 & -.07 \\
\hline $\begin{array}{l}\quad \text { Clarification/ } \\
\text { negotiation }\end{array}$ & -.11 & .20 & .08 & -.03 & -.04 & .21 & .09 & -.07 \\
\hline $\begin{array}{l}\text { Quality of } \\
\text { solutions }\end{array}$ & -.10 & $-.28 *$ & -.24 & .19 & -.18 & .14 & -.19 & -.05 \\
\hline \multirow{2}{*}{\multicolumn{9}{|c|}{$\begin{array}{l}\text { NPDA partner }(N \\
=65) \\
\text { GCICS }\end{array}$}} \\
\hline & & & & & & & & \\
\hline Withdrawal & -.05 & -.04 & -.03 & .13 & .14 & .05 & -.11 & -.20 \\
\hline Dominance & -.07 & $.29 *$ & $.38 * *$ & .05 & .02 & .18 & $.30^{*}$ & .05 \\
\hline $\begin{array}{l}\text { Criticism } \\
\text { and Hostility }\end{array}$ & .11 & $.31 *$ & $.39^{* *}$ & .03 & .17 & .19 & $.29 *$ & .08 \\
\hline $\begin{array}{l}\text { Support-valid } \\
\text { ation }\end{array}$ & $-.26^{*}$ & -.15 & $-.31 *$ & $-.31 *$ & -.24 & .09 & -.22 & -.09 \\
\hline $\begin{array}{l}\text { Problem } \\
\text { solving skills }\end{array}$ & .07 & .14 & -.05 & $-.26^{*}$ & -.13 & .11 & .08 & .08 \\
\hline $\begin{array}{l}\text { Clarification/ } \\
\text { negotiation }\end{array}$ & .07 & .14 & -.05 & $-.26^{*}$ & -.13 & .11 & .08 & .08 \\
\hline $\begin{array}{l}\text { Quality of } \\
\text { solutions } \\
\text { EOI }\end{array}$ & -.07 & $-.25 *$ & -.19 & -.07 & -.15 & .15 & -.02 & .02 \\
\hline Intrusiveness & -.03 & .23 & .04 & .05 & .03 & .17 & .17 & -.01 \\
\hline self-sacrifice & .03 & .01 & .12 & .08 & .13 & .14 & .13 & .22 \\
\hline
\end{tabular}

* Correlation is significant at the 0.05 level (2-tailed).

** Correlation is significant at the 0.01 level (2-tailed). 
Table 5. Correlations of marital adjustment and PDA severity

\begin{tabular}{|c|c|c|c|c|c|c|c|c|}
\hline $\begin{array}{l}\text { Marital self-report } \\
\text { Variables }\end{array}$ & $\begin{array}{l}\text { PDA clinical } \\
\text { severity } \\
\text { (ADIS-IV-L) }\end{array}$ & $\begin{array}{c}\text { Fear of } \\
\text { bodily } \\
\text { sensations } \\
\text { (BSQ) } \\
\end{array}$ & $\begin{array}{l}\text { Catastrophic } \\
\text { thoughts } \\
\text { (ACQ) }\end{array}$ & $\begin{array}{c}\text { Agoraphobic } \\
\text { avoidance } \\
\text { (accompanied) } \\
\text { (MIAa) }\end{array}$ & $\begin{array}{c}\text { Agoraphobic } \\
\text { avoidance } \\
\text { (unaccompanied) } \\
\text { (MIAu) }\end{array}$ & $\begin{array}{l}\text { Severity of } \\
\text { anxiety } \\
\text { Symptoms } \\
\text { (BAI) } \\
\end{array}$ & $\begin{array}{c}\text { Fear of } \\
\text { consequences } \\
\text { of anxiety } \\
\text { (ASI) } \\
\end{array}$ & $\begin{array}{c}\text { Severity of } \\
\text { depression } \\
\text { symptoms } \\
\text { (BDI-II) } \\
\end{array}$ \\
\hline \multicolumn{9}{|l|}{ PDA spouse $(N=65)$} \\
\hline $\begin{array}{l}\text { Marital adjustment } \\
\text { (DAS-4) }\end{array}$ & -.16 & $-.31 *$ & $-.46^{* *}$ & -.12 & -.12 & -.15 & $-.49 * *$ & $-.26^{*}$ \\
\hline \multicolumn{9}{|l|}{ NPDA partner $(N=65)$} \\
\hline $\begin{array}{l}\text { Marital adjustment } \\
\text { (DAS-4) }\end{array}$ & -.15 & -.20 & $-.39 * *$ & -.11 & .03 & -.11 & $-.32 *$ & -.15 \\
\hline
\end{tabular}

* Correlation is significant at the 0.05 level (2-tailed).

** Correlation is significant at the 0.01 level (2-tailed). 
Table 6. Hierarchical regression analysis for interaction marital variables predicting PDA symptom severity $(\mathrm{N}=65)$

\begin{tabular}{|c|c|c|c|c|}
\hline $\begin{array}{l}\text { Step and predictor variables } \\
\text { PDA clinical severity (ADIS-IV-L) } \\
\text { Step } 1 \\
\text { Marital problems caused by PDA } \\
\text { Step } 2 \\
\text { Marital problems caused by PDA } \\
\text { Dominance (PDA patient) }\end{array}$ & $\begin{array}{r}R^{2} \\
.07^{*} \\
.14^{*}\end{array}$ & $\begin{array}{c}\Delta R^{2} \\
.07^{*} \\
.07^{*}\end{array}$ & $\begin{array}{c}\beta \\
.27^{*} \\
.27^{*} \\
.26^{*}\end{array}$ & $\begin{array}{l}.07 \\
\\
.07 \\
.07\end{array}$ \\
\hline $\begin{array}{l}\text { Fear of bodily sensations (BSQ) } \\
\text { Step } 1 \\
\text { Household income } \\
\text { Step } 2 \\
\text { Household income } \\
\text { Criticism and Hostility(NPDA partner) } \\
\text { Quality of solutions (PDA patient) }\end{array}$ & $\begin{array}{l}.18^{*} \\
.33^{*}\end{array}$ & $\begin{array}{l}.18^{*} \\
.15^{*}\end{array}$ & $\begin{array}{l}-.43^{* *} \\
-.42^{* *} \\
.31^{* *} \\
-.22^{*}\end{array}$ & $\begin{array}{l}.18 \\
.17 \\
.09 \\
.05\end{array}$ \\
\hline $\begin{array}{l}\text { Catastrophic thoughts (ACQ) } \\
\text { Step } 1 \\
\text { Age } \\
\text { Marital problems caused by PDA } \\
\text { Step } 2 \\
\text { Age } \\
\text { Marital problems caused by PDA } \\
\text { Dominance (NPDA partner) }\end{array}$ & $.23^{* *}$ & $\begin{array}{l}.23^{* *} \\
.16^{* *}\end{array}$ & $\begin{array}{l}.33^{* *} \\
.33^{* *} \\
.36^{* *} \\
.33^{* *} \\
.40^{* *}\end{array}$ & $\begin{array}{l}.11 \\
.11 \\
.13 \\
.11 \\
.16\end{array}$ \\
\hline $\begin{array}{l}\text { Agoraphobic Avoidance accompanied (MIAa) } \\
\text { Step } 1 \\
\text { Household income } \\
\text { Step } 2 \\
\text { Household income } \\
\text { Support-validation (NPDA spouse) }\end{array}$ & $\begin{array}{l}.08^{*} \\
.15^{*}\end{array}$ & $\begin{array}{l}.08^{*} \\
.07^{*}\end{array}$ & $\begin{array}{l}-.31^{*} \\
-.27^{*} \\
-.26^{*}\end{array}$ & $\begin{array}{l}.10 \\
.07 \\
.07\end{array}$ \\
\hline $\begin{array}{l}\text { Agoraphobic Avoidance unaccompanied (MIAu) } \\
\text { Step } 1 \\
\text { Household income } \\
\text { Gender } \\
\text { Duration of PDA }\end{array}$ & $.20^{* *}$ & $.20^{* *}$ & $\begin{array}{r}-.28^{*} \\
.20 \\
.19\end{array}$ & $\begin{array}{l}.08 \\
.04 \\
.04\end{array}$ \\
\hline $\begin{array}{l}\text { Severity of Anxiety symptoms (BAI) } \\
\text { Step } 1 \\
\text { Duration of cohabiting } \\
\text { Duration of PDA } \\
\text { Step } 2 \\
\text { Duration of cohabiting } \\
\text { Duration of PDA } \\
\text { Criticism and Hostility (PDA patient) }\end{array}$ & $.21^{*}$ & $.21^{*}$ & $\begin{array}{r}.39^{* *} \\
-.35^{* *} \\
.40^{* *} \\
-.37^{* *} \\
.29^{* *}\end{array}$ & $\begin{array}{l}.14 \\
.11 \\
.15 \\
.13 \\
.08\end{array}$ \\
\hline $\begin{array}{l}\text { Fear of consequences of anxiety (ASI) } \\
\text { Step } 1 \\
\text { Household income } \\
\text { Step } 2 \\
\text { Household income } \\
\text { Criticism and Hostility (NPDA partner) }\end{array}$ & $\begin{array}{c}.09^{* *} \\
.10^{* *}\end{array}$ & $\begin{array}{l}.09^{* *} \\
.010^{* *}\end{array}$ & $\begin{array}{l}-.30^{*} \\
-.32^{* *} \\
.31^{* *}\end{array}$ & $\begin{array}{l}.09 \\
.10 \\
.10\end{array}$ \\
\hline
\end{tabular}

$* \mathrm{p}<0.05 ; \quad * * \mathrm{p} \quad<0.01$ 